\title{
Molecular Diagnosis of Tomato Spotted Wilt Tospovirus Infection of Peanut and Other Field and Greenhouse Crops
}

\author{
R. K. Jain, Department of Plant Pathology; S. S. Pappu, Department of Entomology; H. R. Pappu and A. K. \\ Culbreath, Department of Plant Pathology; and J. W. Todd, Department of Entomology, University of Georgia, \\ Coastal Plain Experiment Station, Tifton 31793
}

\begin{abstract}
Jain, R. K., Pappu, S. S., Pappu, H. R., Culbreath, A. K., and Todd, J. W. 1998. Molecular diagnosis of tomato spotted wilt tospovirus infection of peanut and other field and greenhouse crops. Plant Dis. 82:900-904.

Tomato spotted wilt tospovirus (TSWV) is a major disease constraint to peanut, tomato, pepper, and tobacco production in Georgia. Rapid molecular diagnosis of TSWV infection in peanut and its molecular studies were severely hampered by the lack of practical and rapid procedures for the extraction and amplification of the genomic nucleic acid. To circumvent this technical constraint, we adapted an immunocapture-procedure (ICP) for enriching the peanut tissue extracts for TSWV, and combined the ICP with a single-buffer, one-tube reverse transcription polymerase chain reaction (RT-PCR) to achieve rapid and reliable amplification of TSWV sequences from peanut. Both leaf and root tissue of peanut provided PCR-quality templates. Immunocapture, RT, and PCR were done in the same tube, allowing higher throughput. The technique was applicable to a wide range of TSWV-susceptible crops such as tomato, pepper, tobacco, gloxinia, and impatiens. Primers derived from the nucleocapsid protein gene as well as from the large RNA of the viral genome were able to amplify the target sequences in a highly specific and reproducible manner. This approach facilitated rapid molecular typing of natural populations of TSWV in Georgia.
\end{abstract}

Tomato spotted wilt virus (TSWV) is the most prolific member of the genus Tospovirus. The virus has become a major constraint on peanut, flue-cured tobacco, tomato, and pepper in Georgia. TSWV is transmitted by two species of thrips in Georgia: the western flower thrips (Frankliniella occidentalis Hinds) and the tobacco thrips (F. fusca Pergande; 20). Annual losses due to the virus are estimated at $\$ 100$ million in Georgia (3).

TSWV consists of three RNA segments, small (S), medium (M), and large (L). The $\mathrm{S}$ and $\mathrm{M}$ RNAs are ambisense in their genome organization, while the L RNA is in negative polarity. The biological and molecular aspects of TSWV and other tospoviruses have been reviewed recently $(6,9,10)$.

Corresponding author: H. R. Pappu

E-mail: hrp@ ifton.cpes.peachnet.edu

Sequences presented in this paper were submitted to GenBank under accession numbers AF048714, $\mathrm{AF} 048715$, and AF048716. Access to the sequence analyses software was provided by the Biological Sciences Computer Resources Center, University of Georgia. Present address of the first author: Division of Plant Pathology, Indian Agricultural Research Institute, New Delhi 110 012, India.

Accepted for publication 20 April 1998.

Publication no. D-1998-0527-01R

(C) 1998 The American Phytopathological Society
Detection of TSWV and other tospoviruses has been demonstrated in tobacco by the use of reverse transcriptase-polymerase chain reaction (RT-PCR). Using degenerate or specific primers derived from the nucleocapsid protein gene (NP gene) or the $\mathrm{L}$ RNA, detection of tospovirus species of one serogroup or those belonging to different serogroups is now possible by amplifying portions of the viral genome $(1,5,10,15,21)$. Most of these reports utilized TSWV-infected tobacco as the source of plant tissue to demonstrate the utility of RT-PCR for TSWV detection. While it is possible to amplify the TSWV genome from host tissues such as tobacco, it is not easy to accomplish the same task from peanut tissue. Application of RT-PCR for the amplification and detection of TSWV infection from peanut and the subsequent molecular studies are particularly hampered by difficulties associated with prolonged extraction procedures involving several steps with organic solvents. These steps were needed to overcome the potential inhibitory effects of polyphenols present in the peanut tissue. Methods that were effective in obtaining RT-PCR quality templates from other crops, such as tobacco, citrus, tomato, and yam $(14,15)$, were not successful for peanut. The objective of this study was to overcome the technical constraints involved in the rapid amplification of TSWV from peanut by applying immunocapture (IC)-RT-PCR. This was shown to be effective in rapid and sensitive detection of several viruses $(7,12,22)$. We report in this paper a rapid, one-tube, single-buffer IC-RT-PCR method for amplification of TSWV from peanut tissue. Furthermore, we adapt and assess the utility of this technique for the amplification of TSWV from several greenhouse and field crops. Preliminary results have been published (8).

\section{MATERIALS AND METHODS}

Virus isolates. Six TSWV field isolates collected from peanut, tobacco, tomato, pepper, gloxinia, and impatiens from various counties in Georgia were used in the present study. Samples were routinely tested for the presence of TSWV by double-antibody sandwich enzyme-linked immunosorbent assay using a kit purchased from Agdia, Inc. (Elkhart, IN).

Pre-treatment and antibody coating. Thin-walled microfuge tubes $(200-\mu \mathrm{l} \mathrm{ca-}$ pacity; Research Products International, Mount Prospect, IL) were first treated for 15 min each in $0.1 \mathrm{~N} \mathrm{HCl}$ and $4 \mathrm{~N} \mathrm{NaOH}$. After each treatment, the tubes were rinsed with PBST (0.02 M phosphate, $0.15 \mathrm{M}$ saline, $0.05 \%$ Tween-20, $\mathrm{pH} 7.5$ ), washed with $95 \%$ ethanol for $15 \mathrm{~min}$, and air-dried at room temperature. The tubes were then coated with $100 \mu \mathrm{l} \mathrm{NP-specific} \mathrm{antibody}$ (Agdia, Inc.) diluted to 1:200 in carbonate coating buffer (0.05 M carbonate, $\mathrm{pH}$ 9.6) and incubated overnight at $4^{\circ} \mathrm{C}$. The tubes were washed three times with sterile distilled water and used immediately, or airdried and stored at $4^{\circ} \mathrm{C}$ until use.

Sample preparation. Infected tissue (1 g) was ground in $9 \mathrm{ml}$ extraction buffer (phosphate-buffered saline, $\mathrm{pH} 7.4$, containing $0.01 \mathrm{M}$ sodium sulfite, $2 \%$ polyvinylpyrrolidone, MW 40,000, $0.02 \%$ sodium azide, $0.2 \%$ powdered egg albumin, and $2 \%$ Tween-20) with a mortar and pestle. The extract was briefly centrifuged and the supernatant $(100 \mu \mathrm{l})$ was added to an antibody-coated microfuge tube. The tube was incubated at room temperature $\left(22^{\circ} \mathrm{C}\right)$ for 2 to $3 \mathrm{~h}$. The extract was discarded and the tube was rinsed three times with distilled water. To destabilize antibody-bound virus particles, $54 \mu \mathrm{l}$ sterile distilled water was added to each tube and the tubes were subjected to two cycles of alternate freezing $\left(-80^{\circ} \mathrm{C}\right.$ for $\left.10 \mathrm{~min}\right)$ and thawing $\left(70^{\circ} \mathrm{C}\right.$ for $5 \mathrm{~min}$ ). The tubes were then transferred to wet ice for RT-PCR. Sap extracts from non-infected tissues were used as control. 
RT-PCR. Reverse transcription and amplification were performed as a one-tube, single-buffer procedure described previously (14), with minor modifications. The PCR reaction $(100 \mu \mathrm{l})$ contained $200 \mathrm{ng}$ each of the primers, 16 to 20 units RNasin (Promega Corp., Madison, WI), 16 units AMV reverse transcriptase (Promega Corp.), 2.5 units Taq Polymerase (Qiagen Inc., Chatsworth, CA), 1× PCR buffer (Qiagen Inc.), $10 \mathrm{mM}$ Dithiothreitol, 1× Q solution (Qiagen Inc.), and $100 \mu \mathrm{M}$ each of the dNTPs (Amersham Inc., Arlington Heights, IL). PCR mix (46 $\mu \mathrm{l})$ containing the above components was added to the tubes containing the template $(54 \mu \mathrm{l})$ that were previously subjected to freeze-thaw cycles, resulting in a final reaction volume of $100 \mu \mathrm{l}$. Two sets of primer pairs were used. The first primer pair (5'ATGTCTAAGGTTAAGCTC- $3^{\prime}$ and $5^{\prime}$ TTAAGCAAGTTCTGTGAG-3') represented the first and last 18 bases of the coding region of the NP gene, respectively (15). The second primer pair (5'AATTGCCTTGCAACCAATTC-3' and 5'ATCAGTCGAAATGGTCGGCA-3') was specific to L RNA (11). Amplification was performed in an automated thermal cycler (GeneAmp 2400; Perkin-Elmer Corp., Norwalk, CT) programmed for one cycle

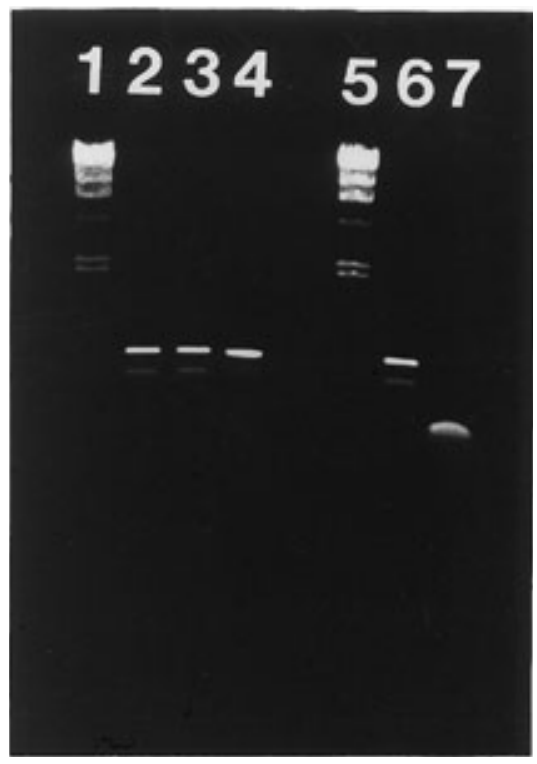

Fig. 1. Agarose gel $(0.8 \%)$ electrophoresis of immunocapture reverse-transcriptase polymerase chain reaction reaction products. Lanes 1 and 5, Lambda DNA digested with HindIII; lane 2, tissue extract from tomato spotted wilt tospovirus-infected peanut leaf; lane 3, tissue extract from infected peanut root; lane 4, amplicon from a DNA clone used as a size standard. Lanes 2,3,4, and 6: primers specific to the nucleocapsid protein gene of the virus. The approximately 800 -base pair (bp) band was indicative of tomato spotted wilt tospovirus-infection. Lane 6, same as in lane 4, used as a size standard; lane 7, primers specific to the Large RNA of the viral genome. The approximately 300-bp band was indicative of tomato spotted wilt tospovirus-infection. of $42^{\circ} \mathrm{C}$ for 45 min for cDNA synthesis, and 40 cycles of amplification with the following parameters: $30 \mathrm{~s}$ of denaturation at $90^{\circ} \mathrm{C}, 2$ min of annealing at $42^{\circ} \mathrm{C}$, and 1 min of extension at $72^{\circ} \mathrm{C}$ followed by one cycle of final extension for $60 \mathrm{~min}$ at $72^{\circ} \mathrm{C}$.

Analysis of PCR products. Following PCR, reaction products $(10 \mu \mathrm{l})$ were analyzed by $0.8 \%$ agarose gel electrophoresis in Tris-borate EDTA (TBE) buffer containing ethidium bromide (17). DNA was visualized and photographed using a UV transilluminator and a Gel Print 2000i gel documentation apparatus (BioPhotonics Corp., Ann Arbor, MI). Lambda DNA digested with HindIII was used as a size standard.

cDNA cloning and sequencing of the NP gene. PCR-amplified DNA from peanut was fractionated on a $0.8 \%$ low melting point agarose gel (Bethesda Research Laboratories, Gaithersburg, MD). The PCR product of expected size (800 base pair [bp]) corresponding to the NP gene was excised under UV light; then the agarose was melted at $65^{\circ} \mathrm{C}$, extracted with equal volumes of phenol:chloroform $(1: 1$, vol:vol), and precipitated (17). The PCR product was ligated into pGEM-T vector (Promega Corp.) and competent Escherichia coli (strain DH5 $\alpha$ ) was transformed by using standard molecular biology procedures (17). Recombinant clones were identified by restriction endonuclease digestion, and selected clones were sequenced (DNA Sequencing Core, University of Florida, Gainesville).

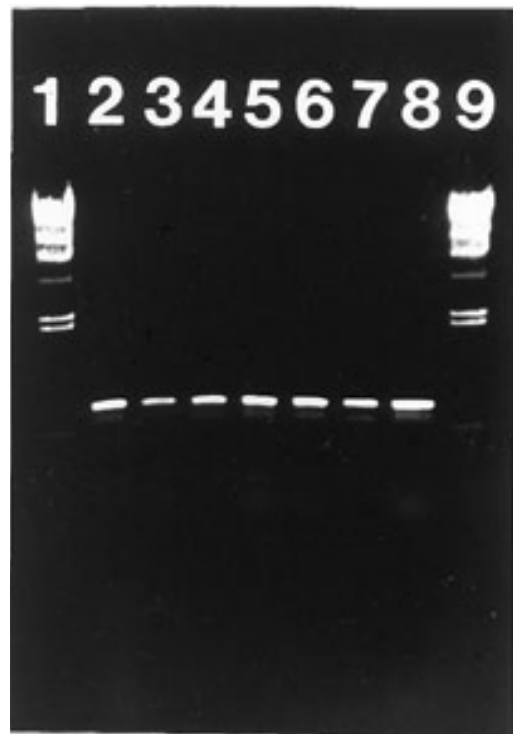

Fig. 2. Agarose gel $(0.8 \%)$ electrophoresis of immunocapture reverse-transcriptase polymerase chain reaction reaction products. Lanes 1 and 9, Lambda DNA digested with HindIII; lanes 2 to 8 , tissue extracts from gloxinia, impatiens, pepper, peanut leaf, peanut root, tobacco, and tomato, respectively. Primers used were specific to the nucleocapsid protein gene of the virus. The approximately 800 -base pair band in lanes 2 to 8 was indicative of tomato spotted wilt tospovirus infection.
Sequence analyses. Sequence data were initially compiled using Seqaid Version 3.6 (16). Multiple alignments were done using CLUSTAL W (19) and cluster analysis was done using TreeView (13). Sequence analyses and sequence comparisons with TSWV sequences available in GenBank (2) were done using the programs of the Genetics Computer Group (4).

\section{RESULTS AND DISCUSSION}

Using antibodies specific to the NP and primers specific to the S or L RNA of TSWV, IC-RT-PCR was successful in amplifying TSWV NP gene from peanut tissue. Both leaf and root tissue of peanut provided template suitable for use in RTPCR, and a major DNA band of expected size (approximately $800 \mathrm{bp}$ ) was observed (Fig. 1, lanes 2 and 3 ) when a S-RNAspecific primer pair was used. A previously characterized tobacco isolate of TSWV (15) was used as a positive control (Fig. 1, lanes 4 and 6). The identity of the amplicon was confirmed by cloning and sequencing. Primers from the L RNA of TSWV were equally effective in amplifying TSWV genome from peanut. The primers used gave a DNA band of expected size ( 300 bp; Fig. 1, lane 7).

IC-RT-PCR was also successful in amplifying the TSWV NP gene from tobacco, tomato, pepper, gloxinia, and impatiens (Fig. 2). A PCR product of expected size (approximately $800 \mathrm{bp}$ ) was observed in all of the crops tested (Fig. 2). No PCR product was obtained from uninfected control samples (data not shown). The identity of these amplicons was confirmed by cloning and sequencing.

The NP genes obtained through IC-RTPCR from naturally infected peanut, tomato, and pepper samples collected from south Georgia were cloned and sequenced. Sequence analyses revealed that all of the clones had an open reading frame of 777 bases and could potentially code for a protein of 258 amino acids, which was in agreement with a previous report (15). The sequences were highly homologous to the NP gene sequences of other TSWV isolates (Fig. 3; 15). Percent identity ranged from 96 to 99 . The minor differences, however, may be of potential significance, because cluster dendrogram of the nucleotide sequences showed that the isolates from Georgia formed one close cluster that was distinct from those reported elsewhere (Fig. 4). A dendrogram using the deduced amino acid sequences gave a similar cluster profile (data not shown).

The objective of this study was to develop a rapid, reliable, and practical method of amplifying TSWV sequences from peanut and other susceptible crops that would facilitate studies on molecular variability among natural populations of the virus infecting various crops in Georgia. The previously available methods that provided good quality template suitable for 
TSWV-HI

TSWV-GA-TC

TSWV-GA-PT

TSWV-GA-TOm

TSWV-GA-Pep

TSWV-HI

TSWV-GA-TC

TSWV-GA-PT

TSWV-GA-TOM

TSWV-GA-Pep

\section{TSWV-HI \\ TSWV-GA-TC \\ TSWV-GA-PT \\ TSWV-GA-TOM \\ TSWV-GA-Pep}

ATGTCTAAGGTTAAGCTCACTAAGGAAAGCATTGTTGCTTTGTTGACACAAGGCAAAGAC - - - - - - - - - - - - - - - - - - - - - - - - - - - - - A - - - - - - - - - - - - - - - - - - - - - - - - - - - - - - - - - - - - - - - - - - - - - - - - - - - - - - - - - - - - - - - - - - - - - - - - - - - - - - - - - - - - - - - - - - - - - - - - - - - - - - - - C- - - - - - - - - - - - - - - CTTGAGTTTGAGGAAGATCAGAATCTGGTAGCATTCAACTTCAAGACTTTTTGTCTGGAA

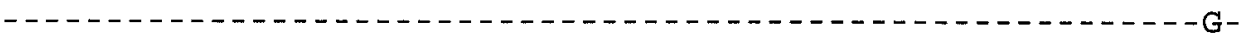

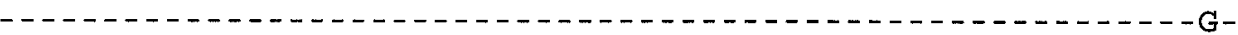

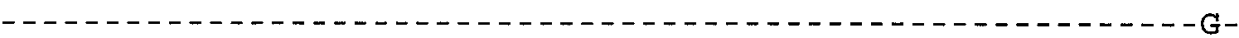

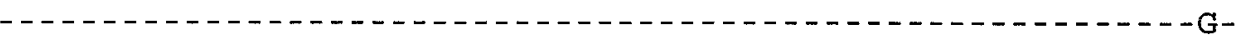

AACCTTGACCAGATCAAAAAGATGAGCATTATTTCATGTCTGACATTCCTGAAGAATCGT

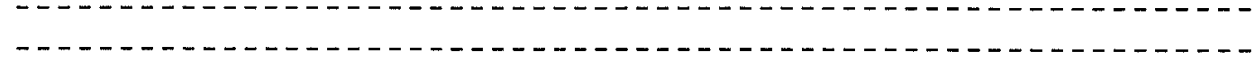
$-\mathrm{T}-$

\section{TSWV-HI}

TSWV-GA-TC

TSWV-GA-PT

TSWV-GA-TOM

TSWV-GA-Pep

TSWV-HI

TSWV-GA-TC

TSWV-GA-PT

TSWV-GA-TOM

TSWV-GA-Pep

TSWV-HI TSWV-GA-TC TSWV-GA-PT TSWV-TOM TSWV-Pep

TSWV-HI TSWV-GA-TC TSWV-GA-PT TSWV-TOM TSWV-Pep
CAGAGCATAATGAAGGTTATTAAGCAAAGTGATTTTACTTTTGGTAAAATTACCATAAAG

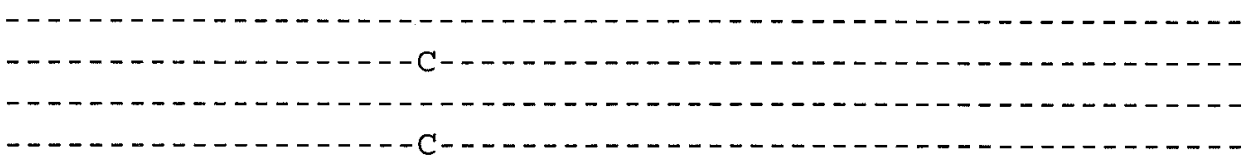

AAAACTTCAGACAGGATTGGAGCCACTGACATGACCTTCAGAAGGCTTGATAGCTTGATC
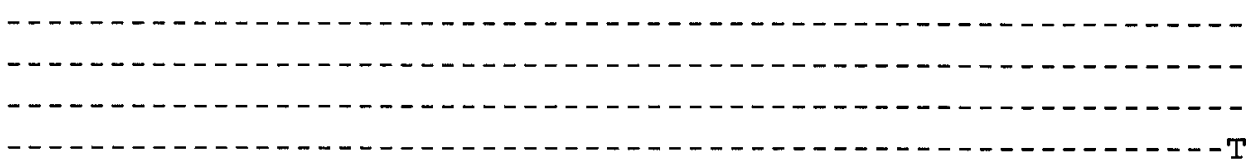

AGGGTCAGGCTTGTTGAGGAAACTGGGAATTCTGAGAATCTCAATACTATCAAATCTAAG
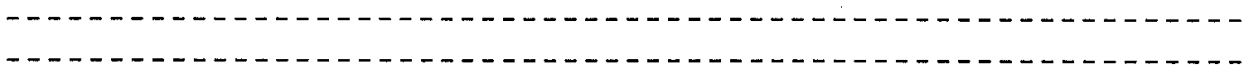

- - - - - - - - - - - - - - - - - - - - - - - - - - - - - - - - - - - - - - - - -

- - - - - - - - - - - - - - - -

ATTGCTTCCCACCCTTTGATTCAAGCCTATGGATTACCTCTTGATGATGCAAAGTCTGTG
TSWV-HI

TSWV-GA-TC

TSWV-GA-PT

TSWV-TOM

TSWV-Pep
ATGATCAGTGTTGTCTTGGCTATATATCAGGATGCAAAATACAAGGACCTCGGGATCGAC - - - - - - - - - - - - - - - - - A- - - - - - - G- - - - - - T- - - - - - - - - - - - - - - - - - - - - - - - - - - - - - - - - - - - - - - - - -

- - - - - - - - - - T- - - - - - - - - - - - - - - - - - - - - - - - - - - T - - - - - - - - - - - - - - - - - -

(continued on next page)

Fig. 3. Multiple alignment of nucleocapsid protein gene sequences (shown as DNA) of tomato spotted wilt tospovirus isolates from peanut (TSWV-PT), tomato (TSWV-Tom), and pepper (TSWV-Pep) from Georgia. Sequence of the tobacco isolate (TSWV-TC) was from Pappu et al., (15). Dashed line indicates an identical base at a given position. Sequence of TSWV-L isolate from Hawaii (GenBank Accession No. X61799), designated here as TSWV$\mathrm{HI}$, was used for comparison as a representative sequence of TSWV isolates reported elsewhere. Primer sequences were underlined. 
Fig. 3. (continued from preceding page)

TSWV-HI

TSWV-GA-TC

TSWV-GA-PT

TSWV-TOM

TSWV-Pep
CCAAAGAAGTATGACACCAGGGAAGCCTTAGGAAAAGTTTGCACTGTGCTGAAAAGCAAA
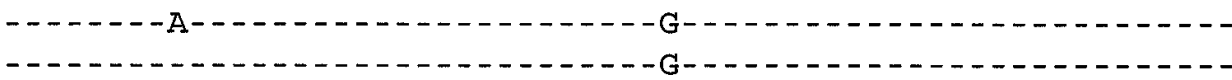

- - - - - - - - - - - - - - - - - - - - - - - - G - - - - - - - - - - - - - - - - - - - -

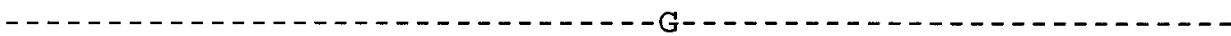

GCATTTGAAATGAATGAAGATCAGGTGAAGAAGGGGAAGGAGTATGCTGCTATACTTAGC

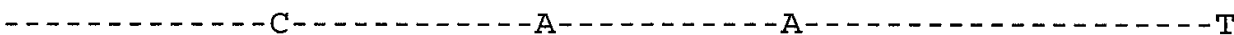

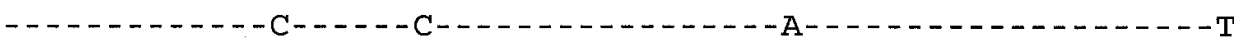

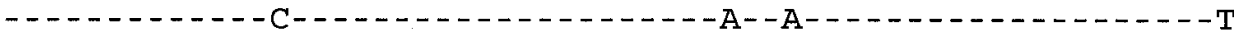

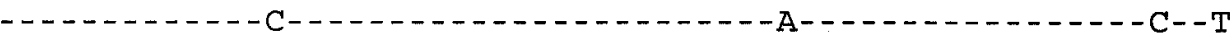

TCCAGCAATCCTAATGCTAAAGGAAGTATTGCTATGGAACATTACAGTGAAACCCTTAAC

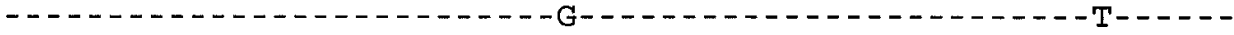

- - - - - - - - - - - C- - - - - - - G- - - - - - - - - - - - - - - - T

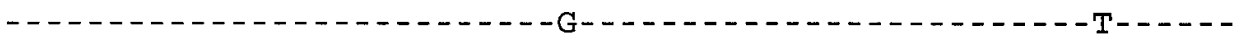

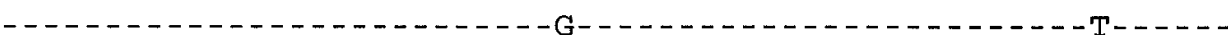

TSWV-HI

TSWV-GA-TC

TSWV-GA-PT

TSWV-TOM

TSWV-Pep

\section{AAGTTCTATGAAATGTTTGGGGTTAAAAAACAGGCAAAACTCACAGAACTTGCTTAA}

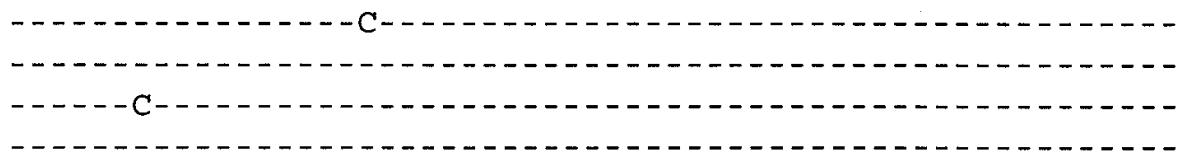

RT-PCR utilized either tobacco or other host tissue. These methods were time-consuming, involving several extractions with phenol:chloroform followed by multiple precipitations. None of them provided templates suitable for RT-PCR from peanut, and thus were not effective in achieving reliable amplification of the TSWV sequences from peanut. Detection of peanut stripe potyvirus in peanut seed by RTPCR was reported previously (18). However, our attempts to utilize that same procedure to amplify TSWV genome from peanut were not successful. A simpler and rapid procedure that would greatly enhance the throughput and thus facilitate molecular characterization of the virus has therefore become necessary.

The procedure described here met all the above criteria in the sense that tissue has to be ground in a buffer, without requiring extractions with organic solvents or ethanol precipitations. Alternate cycles of freezing and thawing prior to RT-PCR were found to be critical, because no amplification of the TSWV NP gene was observed in the absence of this step (data not shown). Two cycles of freezing and thawing were needed for amplification from peanut tissue while one cycle was sufficient for tobacco. Based on the results obtained from other host tissues tested, two freeze-thaw cycles consistently yielded the expected size amplicon. Thermal disruption of immunocaptured virions was also found necessary for plum pox potyvirus detection by IC-RT-PCR (22).

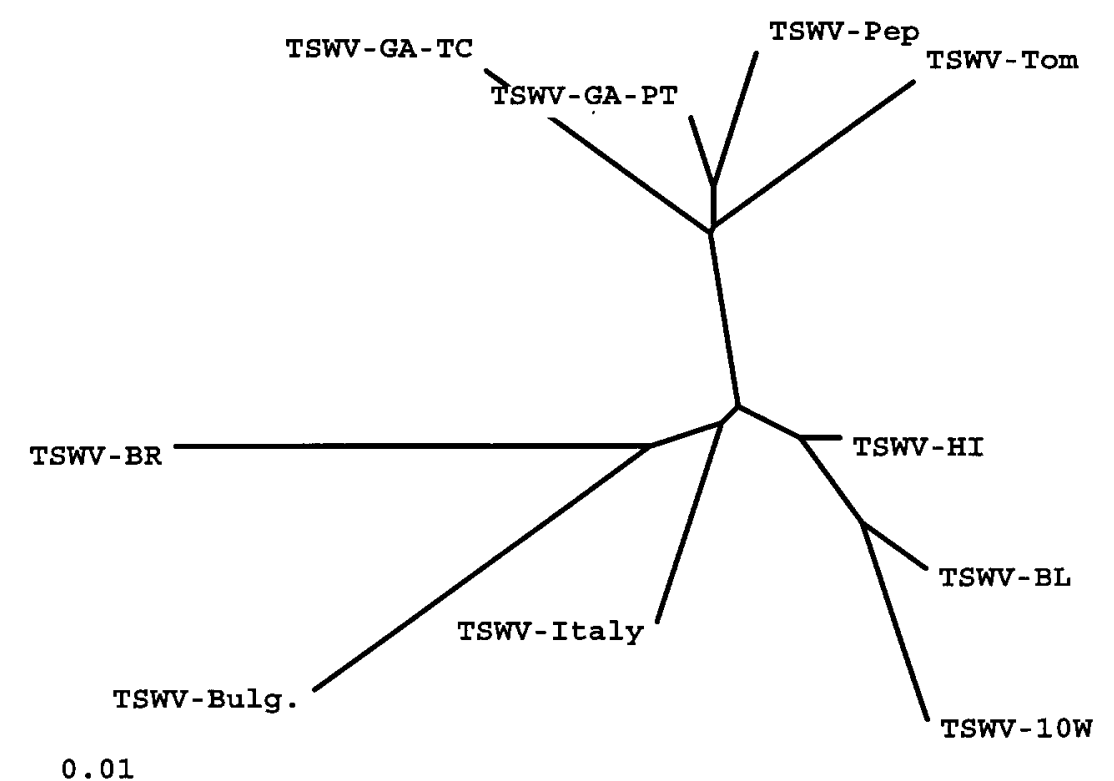

Fig. 4. Cluster dendrogram showing the relationship among the nucleocapsid protein gene sequences of tomato spotted wilt tospovirus (TSWV) isolates from peanut, tomato, and pepper. Sequences for comparison were obtained from GenBank (2). Designations given to each TSWV isolate used in the study: GA-TC, tobacco isolate from Georgia; GA-PT, peanut isolate from Georgia; Pep: pepper isolate from Georgia; Tom, tomato isolate from Georgia; HI, BL, and 10W, Hawaiian isolates; BR, Brazilian isolate; Bulg., Bulgarian isolate.

Besides the ability to amplify TSWV sequences from infected peanut, tomato, pepper, and other crops, the utility of this technique lies in its application to molecular studies on TSWV. In the present study, the amplicons obtained through IC-RTPCR were used for assessing the sequence diversity among natural populations of TSWV. It facilitated the identification of sequences that were unique to the isolates 
from Georgia. While the significance of these differences remains to be investigated, they provide new avenues for developing primers that distinguish them from one another. In spite of the high degree of sequence identity among the NP genes of TSWV isolates used in this study and those reported elsewhere (Fig. 4), it was interesting to note that the cluster dendrograms revealed distinct and discernible differences. The ease and practicality of the ICRT-PCR should make the molecular typing of a large number of isolates either by restriction mapping or sequencing a more feasible study.

The procedure used was rapid and could be done in 1 day. Antisera specific to TSWV-glycoproteins were also effective in IC-RT-PCR (data not shown). Using appropriate antisera and primers, a multiplex format may be developed for peanut for differentiating tospovirus species of one serogroup from those belonging to different serogroups. This procedure was also used for amplifying other peanut viruses, such as peanut stripe potyvirus and a yet uncharacterized potyvirus of peanut, by using appropriate antisera (S. S. Pappu, H. R. Pappu, and D. V. R. Reddy, unpublished). Thus, we showed that using appropriate virus-specific antisera, IC-RT-PCR was effective in amplifying TSWV sequences from peanut and a variety of greenhouse and field crops, thereby facilitating molecular characterization of the virus isolates in different cropping systems.

\section{ACKNOWLEDGMENTS}

We thank the Georgia Agricultural Commodity Commission for Peanut, Georgia Agricultural Commodity Commission for Tobacco, Georgia Seed Development Commission, and Philip Morris Tobacco Company, Inc. for financial support provided to H. R. Pappu; the College of Agricultural and Environmental Sciences, University of Georgia, for S. S. Pappu's postdoctoral fellowship; the Department of Biotechnology, Government of India for R. K. Jain's visiting associateship; and B. Cassidy for helpful advice.

\section{LITERATURE CITED}

1. Adam, G., Peters, D., and Goldbach, R. W. 1996. Serological comparison of tospovirus isolates using polyclonal and monoclonal antibodies. Acta Hortic. 431:135-158.

2. Benson, D. A., Boguski, M., Lipman, D. J., and Ostell, J. 1996. GenBank. Nucleic Acids Res. 24:1-5.

3. Bertrand, P. F. 1997. 1996 Georgia plant disease losses. Univ. Ga. Coop. Ext. Serv., Athens, GA.

4. Devereux, J., Haeberli, P., and Smithies, O. 1984. A comprehensive set of sequence analysis programs for the VAX. Nucleic Acids Res. 12:387-395.

5. Dewey, R. A., Semorile, L. C., and Grau, O. 1996. Detection of Tospovirus species by RTPCR of the N-gene and restriction enzyme digestion of the products. J. Virol. Methods 56:19-26.

6. Goldbach, R., and Peters, D. 1996. Molecular and biological aspects of tospoviruses. Pages 129-157 in: The Bunyaviridae. R. M. Elliott, ed. Plenum Press, New York.

7. Hadidi, A., Levy, L., and Podleckis, E. V. 1995. Polymerase chain reaction technology in plant pathology. Pages 167-187 in: Molecular Methods in Plant Pathology. R. P. Singh and U. S. Singh, eds. CRC Press, Boca Raton, FL.

8. Jain, R. K., Pappu, S. S., Pappu, H. R., Culbreath, A. K., and Todd, J.W. 1997. Detection of tomato spotted wilt tospovirus infection of peanut, tobacco, and vegetables by immunocapture-RT-PCR. Phytopathology 87:S47.

9. Kuo, G. 1996. International Symposium on Tospoviruses and thrips of floral and vegetable crops. Acta Hortic. 431:21-26.

10. Mumford, R. A., Barker, I., and Wood, K. R. 1996.The biology of the tospoviruses. Ann. Appl. Biol. 128:159-183.

11. Mumford, R. A., Barker, I., and Wood, K. R. 1994. The detection of tomato spotted wilt virus using the polymerase chain reaction. J. Virol. Methods 46:303-311.

12. Nolasco, G., de Blas, C., Torres, V., and Ponz, F. 1993. A method combining immunocapture and PCR in a microtitre plate for the detection of plant viruses and sub-viral pathogens. J. Virol. Methods 45:201-218.

13. Page, R. D. M. 1996. TreeView: An application to display phylogenetic trees on personal computers. Comput. Appl. Biosci. 12:357358.

14. Pappu, S. S., Brand, R., Pappu, H. R., Rybicki, E. P., Gough, K. H., Frenkel, M. J., and Niblett, C. L. 1993. A polymerase chain reaction method adapted for selective amplification and cloning of $3^{\prime}$ sequences of potyviral genomes: Application to dasheen mosaic virus. J. Virol. Methods 41:9-20.

15. Pappu, H. R., Culbreath, A. K., Csinos, A. S., and Bertrand, P. F. 1996. Detection of tomato spotted wilt virus in flue-cured tobacco in Georgia by polymerase chain reaction. Tob. Sci. 40:74-81.

16. Rhoads, D. D., and Roufa, D. S. 1985. Emetine resistance of Chinese hamster cells: structure of wild type and mutant ribosomal protein S14 messenger RNA species. Mol. Cell. Biol. 5:1655-1659.

17. Sambrook, J., Fritsch, E. F., and Maniatis, T. 1989. Molecular Cloning: A Laboratory Manual. Cold Spring Harbor Laboratory, New York.

18. Sherwood, J. L., Pennington, R. E., Cassidy, B. G., and Nelson, R. S. 1992. Detection of peanut stripe virus in peanut seed using the polymerase chain reaction. Proc. Am. Peanut Res. Edu. Soc. 24:39.

19. Thompson, J. D., Higgins, D. G., and Gibson, T. J. 1994. CLUSTAL W: Improving the sensitivity of progressive multiple sequence alignment through sequence weighting, positions-specific gap penalties and weight matrix choice. Nucleic Acids Res. 22:4673-4680

20. Todd, J. W., Culbreath, A. K., Chamberlin, J. R., Beshear, R. J., and Mullinix, B. G. 1995 Colonization and Population Dynamics of Thrips in Peanuts in the Southern United States. Pages 453-460 in: Thrips Biology and Management. B. L. Parker, M. Skinner, and T. Lewis, eds. Plenum Press., New York.

21. Weekes, R., Mumford, R. A., Barker, I., and Wood, K. R. 1996. Diagnosis of tospoviruses by RT-PCR. Acta Hortic. 431:159-166.

22. Wetzel, T., Candresse, T., Macquaire, G., Ravelonandro, M., and Dunez, J. 1992. A highly sensitive immunocapture polymerase chain reaction method for plum pox potyvirus detection. J. Virol. Methods 39:27-37. 